\title{
El andaluz en la publicidad: niveles de lengua y contenido del mensaje
}

\author{
Elena Leal Abad \\ Profesora Titular de Universidad \\ Universidad de Sevilla \\ Facultad de Filología \\ Departamento de Lengua Española, Lingüística y \\ Teoría de la Literatura \\ c/Palos de la Frontera s/n \\ 41004 Sevilla \\ lealabad@us.es
}

\section{EL ANDALUZ EN LA PUBLICI- DAD: NIVELES DE LENGUA $Y$ CONTENIDO DEL MENSAJE}

RESUMEN: Las lenguas constituyen productos históricos materializados en una pluralidad de normas en las que conviven usos idiomáticos que son valorados en su percepción por los hablantes, únicos responsables de la atribución de juicios positivos o negativos ante determinadas variantes. La publicidad comercial aprovecha la existencia de ese sistema de actitudes aprobatorias y desaprobatorias que hay en la comunidad hacia la propia realidad lingüistica como estrategia discursiva portadora de valores que trasciende la utilidad práctica inmediata del producto que se está publicitando. De esta manera, aparecen en el componente verbal de los anuncios rasgos dialectales estigmatizados por la modalidad de la distancia comunicativa. El propósito de este estudio trasciende el marco meramente conceptual y trata de validar empíricamente la funcionalidad de la explotación discursiva de la pronunciación andaluza en la publicidad comercial de ámbito local a partir del análisis cuantitativo y cualitativo de las cuñas radiofónicas emitidas por Radio Sevilla (cadena Ser) durante 2018.

PALABRAS CLAVE: pronunciación andaluza; discurso publicitario; oralidad; inmediatez comunicativa; identidad discursiva; estereotipo social.

SUMARIO: 1. La publicidad comercial como objeto de estudio lingüístico. 2. Valor simbólico de los sistemas lingüísticos y de sus modalidades. 3. La complejidad enunciativa del discurso publicitario. 4 . Análisis de las cuñas radiofónicas emitidas por Radio Sevilla (Cadena Ser) durante 2018. 5. Conclusiones

\section{THE ANDALUSIAN LANGUAGE IN ADVERTISING: LANGUAGE LEV- ELS AND MESSAGE CONTENT}

ABSTRACT: Languages are historical products materialized in a plurality of norms where idiomatic usages coexist that are assessed according to their perception by speakers, who are responsible for the attribution of positive or negative views to specific variants. Commercial advertising profits from the existence of such a community system for the approval or disapproval of the actual linguistic reality as a value-carrying discursive strategy which transcends the immediate practical usefulness of the product that is being advertised. Thus, the verbal component of advertisements reveals dialectal features stigmatized by the communicative distance modality. The purpose of this study goes beyond the merely conceptual framework, additionally attempting to empirically validate the functionality associated with the discursive exploitation of Andalusian pronunciation in local commercial advertising from the quantitative and qualitative analysis of radio spots broadcast by Radio Sevilla (Cadena Ser) throughout 2018

KEYWORDS: Andalusian pronunciation; advertising discourse; orality; communicative immediacy; discursive identity; social stereotype.

SUMMARY: 1 . Commercial advertising as a linguistic study object. 2. Symbolic value of linguistic systems and their modalities. 3. The enunciative complexity of advertising discourse. 4. Analysis of radio spots. broadcast by Radio Sevilla (Cadena Ser) throughout 2018. 5. Conclusions.

\section{L'ANDALOU DANS LA PUBLICI- TÉ: NIVEAUX DE LANGUE ET CONTENU DU MESSAGE}

RÉSUMÉ: Les langues sont des produits historiques matérialisés dans une pluralité de normes dans lesquelles coexistent des usages idiomatiques valorisés dans leur perception par les locuteurs, seuls responsables de l'attribution de jugements positifs ou négatifs face à certaines variantes. La publicité commerciale profite de l'existence de ce système d'attitudes d'approbation et de désapprobation existant dans la communauté envers la réalité linguistique elle-même comme une stratégie discursive qui porte des valeurs qui transcendent l'utilité pratique immédiate du produit faisant l'objet de la publicité. De cette manière, des traits de dialecte stigmatisés par la modalité de la distance communicative apparaissent dans la composante verbale des publicités. L'objectif de cette étude dépasse le cadre purement conceptuel et tente de valider empiriquement la fonctionnalité de l'exploitation discursive de la prononciation andalouse dans la publicité commerciale locale à partir de l'analyse quantitative et qualitative des spots radio diffusés par Radio Sevilla (Cadena Ser) en 2018.

MOTS-CLÉS: prononciation andalouse ; discours publicitaire ; oralité ; immédiat communicatif ; identité discursive ; stéréotype social.

SOMMAIRE: 1 . La publicité commerciale comme objet d'étude linguistique. 2. Valeur symbolique des systèmes linguistiques et de leurs modalités. 3. La complexité énonciative du discours publicitaire. 4. Analyse des spots radio diffusés par Radio Sevilla (Cadena Ser) en 2018. 5. Conclusions. $\begin{array}{ll}\text { Fecha de Recepción: } & 30 / 11 / 2020 \\ \text { Fecha de Revisión: } & 21 / 12 / 2020 \\ \text { Fecha de Aceptación: } & 25 / 03 / 2021 \\ \text { Fecha de Publicación: } & 01 / 12 / 2021\end{array}$

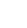




\section{El andaluz en la publicidad: niveles de lengua y contenido del mensaje ${ }^{1}$}

Elena Leal Abad

\section{LA PUBLICIDAD COMERCIAL COMO OBJETO DE ESTUDIO LINGÜÍSTICO}

La publicidad es una práctica discursiva cotidiana adscrita a un contexto socioeconómico determinado: la existencia de la sociedad de consumo y de la competencia de mercado. Desde un punto de vista comunicativo, es una técnica de carácter complejo, propia de las sociedades desarrolladas, que utilizan los productores de bienes y servicios, instituciones o asociaciones para dar a conocer un producto al público y convencerlo para que realice una acción concreta a través de la mediación de profesionales encargados de elaborar el componente icónico y verbal del mensaje, los publicistas. Hay, pues, una finalidad básicamente persuasiva: intentar convencer al receptor para que actúe en cierto sentido o piense de una determinada manera, creando una corriente de opinión favorable hacia el producto, que puede ser una mercancía, un servicio o una ideología. Se trata, sin duda, de una técnica ${ }^{2}$ que se encuentra en continua evolución, tanto desde el punto de vista del diseño como desde la perspectiva de las características lingüísticas y estrategias discursivas vinculadas a los anuncios. Se suele afirmar que nos encontramos ante textos con una clara finalidad info-persuasiva cuyo efecto perlocutivo se puede concretar en algunas de las siguientes acciones: comprar/consumir (publicidad comercial), cambiar hábitos/crear corrientes de opinión (propaganda) o informar de un servicio, de un deber o de un derecho (publicidad institucional), entre otros. No obstante, hay que tener en cuenta que todos estos efectos deben venir precedidos de una estrategia cognitiva previa en la que se concentra toda la persuasión publicitaria: el paso de una relación objetiva entre el producto y su utilidad real a una relación simbólica de valores asociados, determinado por la posesión de los objetos o por las actitudes adoptadas. Así, por ejemplo, el consumo de un determinado detergente podría asociarse al respeto al medio ambiente o el ejercer el derecho al voto, con la imagen de un ciudadano responsable. Partimos de la hipótesis de que en esta creación de valores asociados a las marcas puede tener un papel relevante la

\footnotetext{
1 Este trabajo se ha realizado en el marco de los proyecto de investigación "Tradicionalidad discursiva e idiomática, sintaxis del discurso, traducción y cambio lingüístico en la historia del español moderno: prosa (pre-)periodística/ensayística y literaria" (PGC2018097823-B-100), financiado por el Ministerio de Ciencia, Innovación y Universidades, y "Construcción histórica y proyección social de la imagen del habla andaluza", financiado por la Consejería de Economía y Conocimiento de la Junta de Andalucía. 2 Además del componente idiomático, en el que priman los recursos lingüísticos y estrategias discursivas dirigidos a ponderar el producto y los beneficios de su consumo (Adam y Bonhomme 2000, Robles 2004a), son muchos los códigos que solidariamente intervienen en la creación de sentidos: los colores, la tipografia, la disposición del texto, el timbre de voz, el empleo de componentes icónicos... Todos estos elementos, que no pueden ser ignorados para dar cuenta del sentido que generan los textos, conforman valores asociados a las marcas o entidades a las que se vinculan los productos.
} 
presencia de modalidades marcadas con respecto al eje vertebrador que constituye el estándar en las diferentes zonas hispanohablantes.

Los estudios dedicados a la publicidad en el ámbito hispánico han sido enfocados desde los más diversos ángulos, entre los que cabe señalar los centrados en el enfoque retórico. Contamos con un importante número de trabajos de investigación y, sobre todo, de manuales que nos describen el lenguaje de la publicidad desde diferentes sectores comerciales y perspectivas en sincronia, partiendo de las herramientas metodológicas que proporcionan los planteamientos pragmáticos-textuales $^{3}$ o desde el punto de vista normativo ${ }^{4}$ El manual de Salvador Gutiérrez Ordóñez (1997) constituye un buen ejemplo de aplicación de propuestas pragmáticas a ejemplos concretos de anuncios en español. No obstante, los trabajos centrados en la presencia de rasgos no estándares en la publicidad actual son más escasos ${ }^{5}$, de ahí que planteemos un estudio innovador dentro de un área ampliamente explotada.

\section{VALOR SIMBólico DE LOS SISTEMAS LINGÜÍSTICOS Y DE SUS MODALIDADES EN LA ARTICULACIÓN VERBAL DEL CONTENIDO DEL MENSAJE PUBLICITARIO}

En la actualidad, el uso de lenguas diferentes al español en la publicidad dirigida a un target $^{6}$ hispanohablante constituye un fenómeno discursivo altamente connotativo (no vinculado a la necesidad de crear productos exportables internacionalmente), dado que introduce en el mensaje tópicos e isotopías muy alejados del valor comercial de los productos, dirigidos precisamente a dotar a las firmas de ciertas connotaciones que, en el seno de la comunidad sociocultural en la que se mueve, se asocia a valores y actitudes que traspasan la mercancía en cuestión ${ }^{7}$, ya que existe una conciencia colectiva que vincula identidades sociales e identidades lingüisticas. En otras palabras, en la búsqueda constante de la identidad colectiva se encuentra en la lengua uno de los elementos de mayor capacidad cohesiva:

"Las lenguas, al ser técnicas que se van construyendo históricamente y que, mientras se hablen, no cesan de evolucionary transformarse, se plasman en usos idiomáticos que presentan divergencias, que seaprovechan para poner de relieve peculiares identidades lingüísticas dentro de una misma lengua" (Narbona 2009:28).

En este sentido, la publicidad puede violentar conscientemente el acuerdo implícito de crear enunciados interpretables recurriendo a

3 Cf. Bürki (2005), Escribano (2018), Ferraz (2004), Hernando (1984), Rey (1999), Robles y Romero (2010).

4 Cf. Gómez y Robles (2014).

5 De los trabajos que analizan cómo la variación dentro de una misma lengua (en nuestro caso, el español) ha sido aprovechada como estrategia publicitaria para adecuar el discurso al grupo social al que este se dirige, cabe señalar Robles (2004a). 6 Tecnicismo con el que en ámbito publicitario se hace referencia al "público objetivo" o "diana" del producto.

7 Así, el uso del inglés como código lingüístico exclusivo o en alternancia con el español connota al producto publicitado con valores como modernidad, carácter internacional, éxito y estatus social. Precisamente, la campaña publicitaria "Lengua madre solo hay una" con la que la Real Academia Española y la Academia de Publicidad alertaron en 2016 del abuso de los anglicismos en publicidad se fundamentaba en el valor simbólico asociado a las lenguas extranjeras en la publicidad en español. 
lenguas diferentes de la esperada por el receptor a la hora de codificar todo el texto o parte del mismo. Este recurso desempeña un papel importante como estrategia discursiva, dado que su uso se carga de diversas connotaciones a partir de una operación metonímica de los valores que suelen asignarse tópicamente a los países de procedencia ${ }^{8}$. Al igual que ocurre con la presencia de sistemas distintos al español, también las modalidades o, al menos algunas de ellas, se connotan de valores simbólicos dentro de la publicidad actual en español, contribuyendo a engrosar el espacio de creencias en torno a una sociedad determinada.

La variación interna en la que se materializan de forma natural e inevitable las lenguas y que se concreta en usos idiomáticos diferenciados en los distintos planos lingüísticos es valorada en su percepción por los propios hablantes, que desarrollan significados adicionales a la mera funcionalidad práctica de la comunicación, incluso si tal recepción es involuntaria, como ocurre en el circuito comunicativo publicitario. Este sistema de valores subyacente compartido en una comunidad lingüística es aprovechado estratégicamente por los publicistas. Así, en la mente de los potenciales consumidores se activan de manera automática esquemas de conocimiento mediante los cuales se tienden a atribuir características (rasgos de personalidad, conductas, idiosincrasia, afinidades, virtudes, etc.) comúnmente asociadas a los hablantes incluidos en una determinada categoría. Esta "imagen lingüística", como toda selección que conforma un icono, implica la simplificación de una realidad compleja, pero es precisamente esta reducción la que la avala como estrategia. Dentro del mosaico de variedades internas del español, las modalidades andaluzas han sido de las más utilizadas con este objetivo, hecho probablemente motivado por la acusada personalidad de su pronunciación, que favorece la rápida identificación.

No es nuestro objetivo detenernos en la visión que la publicidad difunde de la realidad andaluza como referente administrativo, politico, cultural y social ${ }^{9}$ ni en el simbolismo que la región posee, representado a través de los paradigmas de las tradiciones, la riqueza natural y las celebraciones. Tampoco constituye nuestro propósito analizar los prejuicios o tópicos asociados históricamente a esta variedad dialectal, para lo que existen trabajos especializados ${ }^{10}$ en los que se examinan las actitudes victimistas, de carácter reivindicativo ante la supuesta discriminación, marginación, desprecio o menosprecio de la modalidad andaluza ${ }^{11}$. Queda fuera de nuestro ámbito de estudio también la

8 Los códigos tienen asociados valores que prevalecen incluso si el receptor no es competente idiomáticamente en ellos: francés (elegancia, distinción, lujo, exclusividad), alemán (robustez, fortaleza, técnica), inglés (modernidad, carácter internacional, éxito, ciencia y estatus social). Este tipo de valores connotativos son muy rentables por las asociaciones que se establecen entre bienes de consumo y países de origen.

9 En este sentido, Lasso (2005) establece un recorrido histórico por sectores comerciales del simbolismo de la región andaluza en una serie de anuncios gráficos vinculados a la alimentación, la perfumería y cosmética, los servicios médicos y la limpieza, entre otros. La autora no entra en el análisis de rasgos lingüísticos vinculados a la modalidad andaluza, sino que su estudio parte más bien del diseño. 10 Cf. Méndez-García de Paredes (1997, 2003, 2009, 2019) y Morillo (2003).

11 “....] en la región andaluza no han faltado manifiestos reivindicadores, como el impulsado por el Partido Andalucista en 1997 bajo el lema "Habla bien, habla andaluz" [...] No muy distinto fue el propósito de la campaña institucional "Habla andaluz siempre". 
promoción institucional que se ha dado a las modalidades lingüisticas que conviven en Andalucía ${ }^{12}$. Este estudio se centra en el empleo instrumental del español en la publicidad comercial, pero no desde una óptica prescriptiva ni retórica, sino más bien desde una perspectiva pragmática en la que analizar la presencia y funcionalidad de las hablas andaluzas y de sus rasgos más característicos en una selección de cuñas radiofónicas difundidas en el ámbito local. De este modo, me voy a centrar en dos cuestiones fundamentales: en primer lugar, en tratar de dilucidar qué conjunto de rasgos lingüísticos de pronunciación configura el andaluz prototípico que se utiliza como estrategia publicitaria en los anuncios seleccionados; en segundo lugar, en vincular la presencia de estos rasgos a ámbitos comerciales específicos. La elección del plano fonético se justifica dado que la especificidad lingüistica del andaluz se rastrea casi de manera exclusiva en la pronunciación.

Para acometer este análisis, partiremos de las actuales concepciones de la lingüística de las variedades ${ }^{13}$, dado que la variación lingüística puede ser utilizada, tal y como se indicó anteriormente, como un marcador de identidad, tanto a nivel personal como en esferas de carácter social o grupal a partir de la valoración asociada a determinados usos idiomáticos. Partiendo de la lingüística variacionista ${ }^{14}$, el propósito de este estudio trasciende el marco meramente conceptual y trata de validar empíricamente la explotación discursiva de la variación lingüística en el ámbito de la publicidad en es-

12 Según el artículo 213 del Estatuto de Andalucía, "Los medios audiovisuales públicos promoverán el reconocimiento y uso de la modalidad lingüistica andaluza, en sus diferentes hablas".

13 El presente trabajo toma como marco teórico el modelo de análisis de Koch y Oesterreicher (1990[2007]), que distingue entre el lenguaje de la inmediatez comunicativa (oralidad) y el lenguaje de la distancia (escrituralidad) basándose en una concepción más o menos formal del discurso. Según estos autores, las modalidades lingüísticas se sitúan en una escala limitada por dos polos opuestos: la inmediatez y la distancia comunicativa. Ambos se identifican con oralidad y escrituralidad respectivamente, conceptos que pertenecen al ámbito de la concepción (en el sentido de más o menos formal) y que son independientes del medial, que se refiere al canal fónicoauditivo (oral) o gráfico-visual (escrito) por el que se transmite el mensaje. La habitual identificación entre los planos oralidad-oral y escrituralidad-escrito se explica porque lo más frecuente es que los modelos de la inmediatez utilicen la realización fónica pasajera frente a los pertenecientes a la distancia, más afines a la gráfica perdurable. 14 Como sabemos, al existir históricamente, el fenómeno del lenguaje se materializa en numerosos tipos de variedades diferentes: lenguas distintas, variedades diatópicas (dialectos) dentro de esas lenguas, variedades sociales (sociolectos) o variedades diafásicas (registros) que empleamos en las distintas situaciones de la vida. Quiere esto decir que ni siquiera dentro de una lengua determinada todas las normas o convenciones son comunes. El hablante cuenta con opciones lingüísticas en los diferentes niveles lingüísticos (López Serena 2013). Ahora bien, hay que tener presente que no todas ellas cuentan con la misma valoración social. Igualdad teórica no debe identificarse, pues, con igualdad de adecuación. La organización de esta variación se explica a partir del modelo teórico-concepcional desarrollado por P. Koch y W. Oesterreicher. De esta manera, en situaciones de máxima formalidad se espera que los discursos carezcan o, mejor dicho, minimicen la presencia de rasgos marcados o dotados de poco prestigio. No obstante, en la inmediatez comunicativa es habitual encontrar rasgos vinculados a las modalidades geográficas y variedades alejadas del estándar convencional. Los anuncios publicitarios simulan a menudo en el segundo nivel de enunciación dramatizaciones en las que los personajes se encuentran en situaciones propias de la oralidad comunicativa, es decir, en entornos de inmediatez poco formales. Por lo tanto, constituyen esas "escenas de vida" el entorno natural en el que fingir un menor control sobre la variedad estándar $\mathrm{y}$, por lo tanto, donde recrear un afloramiento de rasgos macados diatópicamente. 
pañol, que aprovecha el valor identificador de las lenguas y de sus modalidades para caracterizar identidades. De esta manera, aparecen en el discurso rasgos dialectales estigmatizados por la modalidad propia de la distancia comunicativa, que es en la que habitualmente se articula el discurso publicitario, con finalidades muy diversas.

\section{LA COMPLEJIDAD ENUNCIATIVA DEL DISCURSO PUBLICITARIO: FUNCIONALIDAD DE LA NORMA ESTÁNDAR VS. LAS VARIEDADES DIALECTALES}

Como lenguaje especial que es y dada su función social, la práctica totalidad de la actividad profesional lingüística en los medios de comunicación se mueve en el ámbito de la distancia comunicativa. En este sentido, la publicidad se articula mayoritariamente, dado el amplio dominio de acción al que pretende llegar, en la modalidad estándar. Así, el carácter suprarregional de esta norma permite llegar a una audiencia mayor que la que abarcaria, sin provocar "desarraigo lingüístico", una modalidad marcada. No hay que olvidar otras propiedades que hacen del estándar la más conveniente en estos productos discursivos. Nos referimos al hecho de que es la variedad que cuenta con el mayor abanico de recursos expresivos (logrado a través de la ejercitación en el devenir histórico a partir de un doble proceso de elaboración extensiva e intensiva), a la vinculación que se establece entre objetividad (variedad estándar) y subjetividad (variedad marcada) y, finalmente, al mayor prestigio asociado al registro culto.

La necesidad de adecuarse y aproximarse a los diferentes targets ha originado una segmentación de formas, que implica la explotación (basada en la elección estilística ante determinadas variantes lingüísticas) de usos no ejemplares del español (Robles 2004b). Tomando como premisa este empleo mayoritario de la variedad estándar en la publicidad actual, se hace necesario abordar, como estrategia creativa, los denominados "estilos publicitarios", fenómeno que implica seleccionar determinados rasgos cuya elección se refleja en la superficie del texto, tanto de forma verbal (léxico, construcción textual, estructuras sintácticas, pronunciación...) como extraverbal (elección del elemento icónico, de la tipografia...). En la evolución histórica del discurso mediático se observa una mayor frecuencia de modalidades no estándares en la publicidad actual, una presencia en la que la forma de hablar se categoriza y configura identidades (habla como un joven, como un profesor, como una madre, como un andaluz...). Esta presencia de rasgos marcados determina diferentes estilos publicitarios, condicionados tanto por el ramo o sector comercial al que pertenece el producto como por el grupo específico al que este se dirige (Robles y Romero 2010). A modo de ejemplo: el mercado ha considerado el segmento sociodemográfico de la población joven como un potencial de consumo; de esta manera, los medios se nutren de los registros juveniles, adscritos a los parámetros de complicidad, privacidad y expresividad que crea la ficción y que permiten al consumidor reconocer experiencias propias de vida. Y es que la identificación con la "escena de vida" es clave para lograr ese efecto cognitivo previo al consumo del que hablábamos al prin- 
cipio: asociar valores adicionales a la función práctica del producto.

Como todo acto comunicativo, la comunicación mediática pone en relación dos instancias: una de producción y otra de recepción, pero, en el caso específico de la publicitaria, esta se concibe abiertamente como una relación de sentido único. Al observar la publicidad con un poco de detenimiento, nos encontramos ante una variedad de voces que buscan captar nuestra atención. No es la voz del publicista o de la institución que encarga el anuncio. Son voces diversas, muchas veces una intercalación de ellas, las encargadas de transmitir el mensaje (Bürki 2005). La complejidad afecta, pues, de lleno al sistema emisor y receptor en la comunicación publicitaria. Las cadenas televisivas y radiofónicas acogen como modo de financiación estos productos discursivos en los que se distinguen dos niveles de enunciación. Por una parte, la que se establece entre la empresa anunciante (materializada lingüísticamente en la voz en off impersonal que enmarca la dramatización) y el target; por otra, la que se establece en la recreación de una escena de vida entre los personajes ficticios que intervienen en ella, que son los que aparecen caracterizados en su forma de vestir, de actuar y/o pensar y, en determinadas ocasiones, en su forma de hablar. Es en este segundo nivel de enunciación, es decir, en la ficción discursiva creada por el publicita, donde encontramos habitualmente rasgos alejados del estándar prototípico. Precisamente, las cuñas radiofónicas analizadas reconstruyen en su mayoría escenas de estas características: señora a la que se le cierra la puerta por el viento (Cerrajerias Macarena [1]), reproducción de una supuesta conversación prototípica y estereotipada entre madre e hijo (Hipermercado de neumáticos usados "Hipergoma" [7]), conversación entre un jefe de obra y su empleado (Estación de servicio "La Catria" [9]). También en las campañas electorales, en su deseo de acercar el mensaje al ciudadano, la caracterización lingüística juega un papel fundamental como vector de aproximación. Obsérvese en el spot de Ciudadanos ${ }^{15}$ cómo se presenta al candidato a las elecciones autonómicas de 2018 a la Junta de Andalucía, Juan Marín, como una persona cercana a la ciudadanía a partir de la recreación de una escena cotidiana, un desayuno en un día laborable en una casa familiar, donde se hacen patentes, por ejemplo, rasgos como la fricatización de la ch- (osho) o la ausencia de la -d- intervocálica. De esta manera, los responsables políticos conectan y sintonizan con los ciudadanos "descendiendo" al "habla real" con el fin de lograr impacto social en el ámbito simbólico.

Con vistas a ofrecer un análisis que nos permita obtener resultados orientativos de tendencias, hemos acotado un corpus específico, que recoge todas las cuñas radiofónicas emitidas por Radio Sevilla (Cadena Ser) durante 2018 en las que aparecen modalidades vinculadas a las hablas andaluzas. Nos detendremos no solo en el análisis cuantitativo (proporción de cuñas locutadas en estándar frente a aquellas que presentan una modalidad diatópicamente marcada), sino fundamentalmente en el análisis de la funcionalidad del contraste estándar-vernáculo.

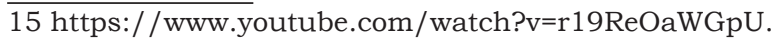




\section{Análisis de las cuñas radiofónicas emitidas por Radio Sevilla (Cade- NA SER) DURANTE 2018}

De acuerdo a los datos facilitados por Radio Sevilla (Cadena SER), a la que agradecemos su colaboración, en 2018 se emitieron alrededor de 2.500 trabajos publicitarios diferentes, entre cuñas, promociones y micro-espacios. De ese total, 34 presentan en distinta proporción rasgos asociados a la pronunciación de las hablas andaluzas. Así, desde el punto de vista cuantitativo, vemos que la proporción, tal y como cabía esperar, es muy pequeña: $1.4 \%$. Ofrecido el dato cuantitativo, nos interesa centrarnos a continuación en dos aspectos. El primero, identificar los rasgos lingüísticos de pronunciación que suponen una elección estilística entre el conjunto de variantes lingüisticas y explicar brevemente la valoración social vinculada a ellos; el segundo, establecer la funcionalidad como estrategia publicitaria que tiene la caracterización idiomática de los sujetos discursivos.

\subsection{Presencia de rasgos de pronunciación}

Acotaremos siete rasgos de pronunciación, compartidos en su mayoria por otras modalidades del ámbito hispánico: presencia de una "s" dental (no apical), neutralización de los fonemas /s/ y / $\theta /$ (fenómenos denominados ceceo y seseo), modificación de la -s llamada implosiva (la situada en final de sílaba o palabra, pronunciación aspirada de la jota (y $g$ ante $e, i$ ), igualación de $-\mathrm{R}$ y $-\mathrm{L}$ implosivas (finales de sílaba o de palabra), pronunciación africada de la ch y caída de /d/ en posición intervocálica. Es importante tener en cuenta que no todos estos rasgos tienen igual potencia identitaria. Muy débil es la conciencia de la pronunciación floja y relajada del sonido que se escribe con $j$ (o $g$ ante $e, i$ ). Entre los rasgos que no gozan de prestigio se encuentra la fricatización de la ch o la neutralización de $r / l$ en posición implosiva.

Como decíamos anteriormente, una rápida ojeada a los anuncios publicitarios actuales nos hace caer en la cuenta de que las tradicionales figuras planas de emisor y receptor han de someterse a ciertas adaptaciones para explicar el proceso comunicativo en este campo. De esta manera, en los discursos se inscriben voces distintas a las de las personas fisicas del hablante y el oyente o de los responsables y destinatarios sociales del contenido. El estudio de cómo se recurre a la teoría polifónica de la Enunciación a la hora de construir campañas publicitarias resulta muy interesante, porque permite descubrir cómo el redactor publicitario emplea puntos de vista diferentes al suyo a través de los sujetos discursivos, que son entes ficcionales con un enorme potencial argumentativo (Bürki 2005). ¿Quiénes son estos entes ficcionales en las cuñas analizadas? Podemos observar en la tabla de la derecha los sujetos discursivos que presentan en sus intervenciones rasgo andaluces: 


\begin{tabular}{|c|c|}
\hline IDENTIFICACIÓN DE LA CUÑA PUBLICITARIA & $\begin{array}{l}\text { SuJETOS DISCURSIVOS QUE PRESENTAN RASGOS ANDALUCES DE } \\
\text { PRONUNCIACIÓN }\end{array}$ \\
\hline [1] Cerrajería Macarena & $\begin{array}{l}\text { Una vecina le cuenta a otra cómo se le cerró la puerta } \\
\text { con las llaves en el interior de la casa y cerrajería } \\
\text { Macarena resolvió con gran rapidez el problema. }\end{array}$ \\
\hline [2] "Ramsol". Toldos y rótulos & $\begin{array}{c}\text { Varias mujeres responden a coro a una voz masculina } \\
\text { que les plantea diferentes circunstancias en las que } \\
\text { convendria instalar un toldo o rotular. }\end{array}$ \\
\hline [3] Azulejos Pantoja (bañeras) & $\begin{array}{l}\text { Mujer que reproduce un refrán popular ("como en } \\
\text { casa en ningún sitio") }\end{array}$ \\
\hline [4] Azulejos Pantoja (cocinas) & $\begin{array}{c}\text { Una voz femenina que habla en soliloquio y después } \\
\text { con una voz masculina sobre los problemas de } \\
\text { acometer una reforma en su casa. }\end{array}$ \\
\hline [5] Desengrasante "E1 Milagrito" & $\begin{array}{c}\text { Canción (voz masculina) en la que se ensalzan las } \\
\text { propiedades y ventajas del producto. }\end{array}$ \\
\hline [6] Estación de servicios "La Juliana" & $\begin{array}{c}\text { Dos voces masculinas que reproducen el nombre de } \\
\text { la estación de servicio publicitada. }\end{array}$ \\
\hline [7] Hipermercado de neumáticos usados "Hipergoma" & $\begin{array}{l}\text { Una madre da consejos a un hijo mayor de edad } \\
\text { sobre la necesidad de cambiar los neumáticos del } \\
\text { coche. }\end{array}$ \\
\hline [8] Estación de servicio "La Catria" (comandante) & $\begin{array}{l}\text { Se simula una conversación entre una torre de } \\
\text { control y un piloto. }\end{array}$ \\
\hline [9] Estación de servicio "La Catria" (obras) & $\begin{array}{l}\text { Se simula una conversación entre un obrero y un jefe } \\
\text { de obras. }\end{array}$ \\
\hline $\begin{array}{c}\text { [10] Estación de servicio "La Catria" (Manuel Ruiz de } \\
\text { Lopera_Pepe Castro) }\end{array}$ & $\begin{array}{c}\text { Se simula una conversación entre Manuel Ruiz de } \\
\text { Lopera, expresidente del Real Betis Balompié, y Pepe } \\
\text { Castro, presidente del Sevilla Fútbol Club. El Sevilla } \\
\text { F.C y el Real Betis Balompié son eternos rivales en la } \\
\text { ciudad de Sevilla. }\end{array}$ \\
\hline $\begin{array}{c}\text { [11] Estación de servicio "La Catria" (Manuel Ruiz de } \\
\text { Lopera_Joaquín Sánchez) }\end{array}$ & $\begin{array}{c}\text { Se simula una conversación entre Manuel Ruiz } \\
\text { de Lopera, expresidente del Real Betis Balompié, } \\
\text { y Joaquín Sánchez, futbolista español del Betis. } \\
\text { (actualidad humoristica) }\end{array}$ \\
\hline [12] Estación de servicio "La Catria” (Playa) & $\begin{array}{l}\text { Conversación en el seno de un matrimonio para } \\
\text { decidir ir a pasar un día de playa con los niños. }\end{array}$ \\
\hline [13] Estación de servicio "La Catria" (verano) & $\begin{array}{l}\text { Conversación entre Pepe y su compadre sobre las } \\
\text { ventajas de ahorro de la estación de servicio. }\end{array}$ \\
\hline $\begin{array}{l}\text { [14] SER EMPRESARIOS. NEGOCIOS QUE FUNCIO- } \\
\text { NAN. Centro comercial Airesur }\end{array}$ & Modesto García Polo, gerente de Airesur \\
\hline $\begin{array}{l}\text { [15] SER EMPRESARIOS. NEGOCIOS QUE FUNCIO- } \\
\text { NAN. Azulejos del Valle }\end{array}$ & Juan Simón del Valle (gerente de Azulejos del Valle) \\
\hline $\begin{array}{l}\text { [16] SER EMPRESARIOS. NEGOCIOS QUE FUNCIO- } \\
\text { NAN. Azulejos Pantoja }\end{array}$ & $\begin{array}{l}\text { José Javier Pantoja, director general de Azulejos } \\
\text { Pantoja }\end{array}$ \\
\hline $\begin{array}{l}\text { [17] SER EMPRESARIOS. NEGOCIOS QUE FUNCIO- } \\
\text { NAN. Colchones Rupe }\end{array}$ & Isaac Vega, director comercial de Colchones Rupe \\
\hline
\end{tabular}




\begin{tabular}{|c|c|}
\hline $\begin{array}{l}\text { [18] SER EMPRESARIOS. NEGOCIOS QUE FUNCIO- } \\
\text { NAN. Clinicas dental "Deimplant" }\end{array}$ & Eduardo Silva, propietario de la clinica "Deimplant" \\
\hline $\begin{array}{l}\text { [19] SER EMPRESARIOS. NEGOCIOS QUE FUNCIO- } \\
\text { NAN. Cínica dental Raúl Pascual }\end{array}$ & Raúl Pascual, odontólogo \\
\hline $\begin{array}{l}\text { [20] SER EMPRESARIOS. NEGOCIOS QUE FUNCIO- } \\
\text { NAN. Eduardo Castro, concesionario oficial de motos } \\
\text { Yamaha }\end{array}$ & $\begin{array}{l}\text { Eduardo Castro, gerente del concesionario oficial de } \\
\text { motos Yamaha }\end{array}$ \\
\hline $\begin{array}{l}\text { [21] SER EMPRESARIOS. NEGOCIOS QUE FUNCIO- } \\
\text { NAN. Tiendas "El golpecito" }\end{array}$ & Juan José Gil, director de márketing de "El golpecito" \\
\hline $\begin{array}{l}\text { [22] SER EMPRESARIOS. NEGOCIOS QUE FUNCIO- } \\
\text { NAN. Hostal "Nueva Andalucia" }\end{array}$ & $\begin{array}{l}\text { Javier Solano, director gerente del hostal "Nueva } \\
\text { Andalucia" }\end{array}$ \\
\hline $\begin{array}{l}\text { [23] SER EMPRESARIOS. NEGOCIOS QUE FUNCIO- } \\
\text { NAN. "Couch voulez" cocinas }\end{array}$ & Antonio del Valle, director "Couch voulez" cocinas \\
\hline $\begin{array}{l}\text { [24] SER EMPRESARIOS. NEGOCIOS QUE FUNCIO- } \\
\text { NAN. Panaderia "Marchapán" }\end{array}$ & $\begin{array}{l}\text { Francisco Javier Vega Ponce, director gerente } \\
\text { "Marchapán }\end{array}$ \\
\hline $\begin{array}{l}\text { [25] SER EMPRESARIOS. NEGOCIOS QUE FUNCIO- } \\
\text { NAN. Clínica ginecológica de reproducción asistida } \\
\text { "Masvida Reproducción" }\end{array}$ & Javier Suárez, director de "Masvida Reproducción" \\
\hline $\begin{array}{l}\text { [26] SER EMPRESARIOS. NEGOCIOS QUE FUNCIO- } \\
\text { NAN. Cocina tailandesa "Mister Noodles" }\end{array}$ & David Soria, propietario de "Mister Noodles" en Sevilla \\
\hline $\begin{array}{l}\text { [27] SER EMPRESARIOS. NEGOCIOS QUE FUN- } \\
\text { CIONAN. Patatas fritas "Hispalana", elaboración } \\
\text { artesanal. }\end{array}$ & Juan Carlos Mejías, director gerente de "Hispalana" \\
\hline $\begin{array}{l}\text { [28] SER EMPRESARIOS. NEGOCIOS QUE FUNCIO- } \\
\text { NAN. "Perfumerias Ana" }\end{array}$ & $\begin{array}{c}\text { Sergio Martín, director de márketing de "Perfumerias } \\
\text { Ana" }\end{array}$ \\
\hline $\begin{array}{l}\text { [29] SER EMPRESARIOS. NEGOCIOS QUE FUNCIO- } \\
\text { NAN. "Pomodoro" }\end{array}$ & $\begin{array}{l}\text { Paloma Pascual, directora de Innovación de } \\
\text { "Pomodoro" }\end{array}$ \\
\hline $\begin{array}{l}\text { [30] Empresa de tratamiento de humedades "MUR- } \\
\text { PROTEC" }\end{array}$ & $\begin{array}{l}\text { Hombre riéndose al formularse preguntas en tono } \\
\text { desafiante sobre los problemas de las humedades. }\end{array}$ \\
\hline [31] Patatas fritas "Hispalana", elaboración artesanal & $\begin{array}{l}\text { Dos aficionados al fútbol, uno del Betis y otro del } \\
\text { Sevilla, viendo un derbi en el estadio. }\end{array}$ \\
\hline [32] Perfumerias "Ana" & $\begin{array}{l}\text { Intervención de una mujer, que muestra su } \\
\text { entusiasmo ante las promociones de colonias. }\end{array}$ \\
\hline [33] Toldos y carpas "Quitasol" & $\begin{array}{c}\text { Conversación entre Manuel Hidalgo, responsable de } \\
\text { ventas de Toldos "Quitasol" y un potencial cliente } \\
\text { sobre las ventajas de instalar un todo. Canción de } \\
\text { copla de fondo. }\end{array}$ \\
\hline [34] Recambios "Castaños" & $\begin{array}{c}\text { Conversación entre un costalero, encargado de portar } \\
\text { los pasos en Semana Santa, y un capataz, persona } \\
\text { que lo dirige en la procesión. }\end{array}$ \\
\hline
\end{tabular}

Estas 34 cuñas pueden ser divididas en dos grupos: aquellas que simulan la representación de una escena (18) en las que, por lo tanto, el registro sería el propio de la situación representada, y las que se integran en las promociones "Ser empresarios. Negocios 
que funcionan" (16), que obedecen a una estructura fija en la que se inserta, a modo de testimonio, una intervención de un empresario real. No hay, pues, una dramatización en el sentido de que no se recrea una escena, sino que lo que encontramos son intervenciones preparadas para la elocución pública en un espacio publicitario. La planificación varía notablemente entre unos tipos de negocios y otros. Los locutores testimonian de esta manera las ventajas del producto o servicio y proyectan su garantía en el entorno de un espacio fácilmente reconocible para un oyente de la cadena. Dejamos fuera del análisis las voces no personalizadas, que suelen aparecer al inicio o al final del anuncio, ostentando mayor jerarquía y a las que quedan subordinadas las otras voces del discurso. Habitualmente, es una voz en off la que transmite la información referencial (dirección, teléfono, precio) del negocio o producto. Lo estándar se asocia a la eficiencia y claridad comunicativas, dado que la nitidez en la dicción favorece la máxima proyección de la información y evita su posible ambigüedad.

De las 34 cuñas analizadas, vamos a detraer en primer lugar los 16 espacios promocionales "Ser empresarios. Negocios que funcionan", protagonizados por emisores reales (aunque adquieran en el anuncio la condición de sujetos discursivos). En las 18 cuñas en las que aparecen personajes ficticios, hay una mayor presencia de locutores masculinos (11 cuñas) frente a 6 con personajes femeninos. La que queda para completar el total está protagonizada por un matrimonio. La condición sociocultural de las mujeres que aparecen en estas dramatizaciones es en general la de ama de casa con escaso nivel socioeconómico y responde en ocasiones a estereotipos muy caricaturizados, como ocurre con la figura de la madre en la cuña número 7 . En cuanto a los hombres, ofrecen una gama más variada de situaciones comunicativas: conversación profesional entre jefe de obras y albañil, imitadores de personajes conocidos de la actualidad local o reproducciones de escenas lúdicas, tales como la asistencia a un partido de fútbol o el ensayo de un paso en Semana Santa. La voz femenina se asocia a un ámbito más doméstico, frente a la masculina, que trasciende la privacidad para proyectarse en un dominio público (trabajo, ocio, actualidad mediática). Los rasgos no aparecen vinculados, pues, a productos caracterizados por la técnica, la ciencia, el desarrollo o la innovación. Se reproducen escenas de inmediatez comunicativa a través de personajes que desarrollan trabajos para los que no se exige una cualificación.

Los resultados de los 16 espacios promocionales "Ser empresarios. Negocios que funcionan" son más llamativos, dado que solo en una de las cuñas, la 29, aparece una mujer empresaria, que no presenta rasgos diatópicamente marcados. El resto de casos está constituido por puestos de dirección representados por hombres. El perfil profesional de estos empresarios es muy variado, tal y como podemos observar en la tabla que resume los sujetos discursivos.

Hemos analizado hasta ahora la caracterización sociológica de los personajes recreados, que sirve para publicitar productos o servicios vinculados a la alimentación, la fontanería, la limpieza, los combustibles 
o la construcción, entre otros. Conviene ahora determinar los rasgos de pronunciación que aparecen vinculados a cada uno de ellos. En cuanto a la neutralización de los fonemas /s/ y / $\theta /$, las cuñas radiofónicas presentan mayoritariamente la distinción entre ambos fonemas (16 de las 34 analizadas): [1], [2], [4], [5], [7], [8], [9], [14], [15], [17], [19], [22], [25], [26], [29] y [30]). Aparecen 13 casos de seseo ([10], [11], [16], [18], [20], [21], [23], [27], [28], [31], [32], [33] y [34]) y solo 2 hablantes sistemáticamente ceceantes en las cuñas [12] y [24]. El ceceo en el primer caso (['kari a'řeyla a $10^{\mathrm{h}}$ 'nijo ${ }^{\mathrm{h}}$ ke no ' $\beta a m o^{\mathrm{h}}$ a la 'playa i el ome 'nahe ke no ' $\beta a m o^{\text {h }}$ a ‘đa ‘ $\beta$ a a ' $\theta$ e me'nuðo]) se corresponde con un hablante de escaso nivel cultural, cuya forma de hablar contrasta con la de la mujer a quien se dirige, su esposa, que presenta una dicción afectada. El contraste realza el efecto humorístico por contraste. El caso de [24] es diferente, dado que no nos encontramos ante una representación, sino ante el testimonio real de Francisco Javier Vega Ponce, director gerente "Marchapán (en la localidad sevillana de Utrera):

\begin{abstract}
Voz en off 3 (hombre): Pocas cosas hay más placenteras en la vida, como saborear un buen pan y los 37 profesionales de "Marchapán" lo saben. La clave es manejar la mejor materia prima y aderezarla con mucho cariño, así se logran los picos, regañás y panes, que salen de sus hornos, que se encuentran en Utrera.

Voz en Off 2 (mujer): Francisco Javier Vega Ponce es el director gerente de la marca.

Francisco Javier Vega Ponce, director gerente “Marchapán”: [el $\theta$ e'kreto ðe wm bwem pan es 'una 'ßwena elaßora'Өjon um bwem proӨeӨo...empeӨ'e a

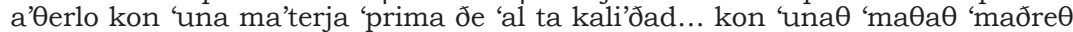
natu'rales i 'wna elaßora' $\theta j o n$ 'lenta 'Өoßre 'toðo 'mui ‘lenta 'para ke el 'pan 'Өea ßas'tante ‘ßweno i espoy'xoso].
\end{abstract}

Es generalizada la pronunciación aspirada de la jota y la modificación de la -s llamada implosiva tiene una incidencia bastante alta: se registra en 23 casos ([2], [4], [7], [8], [9], [10], [11], [12], [13] [15], [16], [17], [19], [20], [22], [23], [24], [25], [27], [28], [29], [33] y [34]. La caída de /d/ en posición intervocálica se atestigua en 10 cuñas: [1], [10], [12], [13], [15], [16], [20], [22], [31] y [34]. Mucha más escasa es la aparición de la igualación de $-\mathrm{R}$ y -L implosivas (finales de sílaba o de palabra): 5 casos ([10], [16], [24], [33] y [34] y de la pronunciación africada de la ch: 6 casos ([1], [11], [13], [17], [20] y [33]). Estos dos últimos rasgos característicos del español hablado en Andalucía tienen un grado de difusión más reducido y, en general, carecen de prestigio en la región. En las cuñas en las que aparecen van acompañadas de vulgarismos de pronunciación: metátesis simple (cocreta [1]), equivalencia acústica (güena [10]), de pronunciaciones de carácter expresivo (jartá de rápido [11], miarma) o propias del ámbito de la Semana Santa (levantá [34]). En [12] encontramos el denominado "heheo"16, es decir, la aspiración

16 "Estrechamente relacionado con el debilitamiento de la fricación velar, así como con la aspiración de la -s implosiva y el seseo-ceceo, está el fenómeno marginal desde el punto de vista geográfico y demográfico, pero muy interesante desde el histórico, de la articulación aspirada de la s- o c- (z) inicial de palabra o sílaba, al que algunos dan el nombre de heheo, que da lugar a pronunciaciones como hí, 'sí'; heño(r), 'señor'; handalia, 'sandalia'; quihe, 'quise'; peheta, 'peseta'; etc." (Cf. Morillo 2011: 225). 
de la s- explosiva, en inicial o interior de palabra: "hí heñó, hón do(h) pehéta".

En este apartado se hace necesario establecer una diferenciación en cuanto al tipo de modalidad empleada entre tipos de negocios y forma lingüística. Para ilustrar esta gradación, tomamos como base los micro-espacios publicitarios "Ser empresarios. Negocios que funcionan" emitidos en 2018, en los que, a partir de una estructura común, se publicitan negocios locales. Estos productos presentan siempre la misma estructura: una voz en off abre y cierra el espacio, pero en el centro de la emisión se da cabida al gerente o director de la empresa que se está publicitando. Ese testimonio se utiliza como proyección de confianza, al validar la garantía de su producto con su testimonio. Es en ellos donde podemos establecer una relación entre forma lingüística y sector comercial. Se establece un contraste entre el área de ciencias de la salud [clínicas dentales ("Deimplant", Raúl Pascual) y clínicas de reproducción asistida ("Masvida reproducción")], donde aparecen rasgos de pronunciación valorados positivamente (distinción $\mathrm{s} / \mathrm{z}$, seseo, pronunciación aspirada de la jota), frente a otros sectores, como la alimentación (patatas Hispalanas, panadería Marchapán), donde afloran rasgos circunscritos a la inmediatez comunicativa: vulgarismos, fricatización de la ch, neutralización $\mathrm{R} / \mathrm{L}$ y heheo.

\subsection{Finalidad de la presencia de variedades marcadas con Respecto al ESTÁNDAR}

La presencia de rasgos marcados diatópicamente en las intervenciones de los sujetos discursivos no solo se explica por el deseo de dotar de mayor realismo idiomático y, por lo tanto, de mayor cercanía a la escena de vida que se está representando. Hay que tener en cuenta, además, que las lenguas y sus modalidades son portadoras de ciertos valores simbólicos: actúan como "señas de identidad colectiva" que aglutinan y dan cohesión a la comunidad, a la vez que sirven para separarla de otras comunidades. Se convierten en "hecho diferencial" Lo dicho para las lenguas, como sistemas, puede hacerse extensivo a los dialectos y a las modalidades lingüísticas (las hablas), cuando estas adquieren un valor simbólico (reconocido como propio desde la misma comunidad y como ajeno desde la comunidad externa). Veamos a continuación qué posibilidades ofrece al publicista, dentro del sistema lingüístico del español, el uso de rasgos vinculados a la modalidad andaluza como estrategia:

(1) Atraer la atención del oyente. Especialmente en el terreno radiofónico, el empleo de una variedad marcada hará captar plenamente la atención del oyente por contraste, dado que lo esperable es que la publicidad se configure en una modalidad cercana al estándar. En este sentido, las cuñas radiofónicas que no aparecen enmarcadas por una voz en off de carácter impersonal sirven para captar esta: [4] Azulejos Pantoja Cocina.

(2) Lograr la empatía/cercanía/proximidad con el receptor al que se dirige el producto. Como decíamos anteriormente, la redacción publicitaria se ha 
especializado debido a la vertiginosa fragmentación del mercado y se ha visto obligada a adecuarse a los diferentes targets, lo que la ha conducido a una segmentación de formas y estilos. Esta estrategia de empatizar lingüísticamente con el destinatario se empleaba tradicionalmente en campañas electorales. En las cuñas analizadas constituye un recurso habitual en la publicidad local de establecimientos propios de la ciudad, en este caso de Sevilla (Perfumerias Ana, ABR Talleres, Mesones "El Serranito").

(3) Acentuar la autenticidad del productor. La modalidad marcada queda asociada a valores de tradicionalidad, elaboración artesanal (frente al carácter industrial), autenticidad. Pensemos, por ejemplo, en cómo se comercializan, dentro del sector de la alimentación, determinados aceites o gazpachos. En esta creación de valores asociados a las mercancias, juega un papel importante la presencia de modalidades marcadas. Así, por ejemplo, en el anuncio de Jamones Molina ${ }^{17}$, la conjunción de una escena rural y tradicional, en consonancia con la caracterización lingüísticas de los sujetos discursivos que aparecen (padre, madre e hijo), vincula esa marca de jamones con el valor de lo auténtico. Obsérvese el contraste entre lo moderno, representado por el hijo, y lo tradicional, relacionado con el padre, cuya actitud revela cierta desconfianza hacia las innovaciones del presente. La modalidad andaluza se relaciona, pues, con la preservación de la tradición frente a las injerencias externas, con el carácter natural e incultivado. Es esta misma asociación entre modalidad lingüistica y autenticidad del producto la que sustenta buena parte de los anuncios publicitarios de Fabada Asturiana Litoral ${ }^{18}$, protagonizados por la tradicional abuela de Litoral, en cuyas intervenciones encontramos rasgos de la pronunciación asturiana, tales como la diptongación del verbo ser y la colocación del pronombre átono después del verbo. Obsérvese también la caída de la dental intervocálica "como tuvo congelao", que se constituye más en una marca difásica (registro informal) que diatópica. Una vez más, la estrategia publicitaria se basa en el contraste entre tradición (autenticidad, valor artesanal) y modernidad, representada en esta ocasión en el efecto humorístico provocado por la irrupción de las redes sociales en un entorno rural.

(4) Caracterizar a los sujetos discursivos que intervienen como personajes en el producto publicitario. El discurso se asocia a un personaje que representa un prototipo, al que se legitima como agente autorizado para avalar el producto o servicio: una limpiadora para anunciar un detergente, un jefe de obra para garantizar el ahorro que supone en combustible repostar en una determinada estación de gasolina. Es en este entorno en el que las cuñas publicitarias analizadas vinculan el uso del andaluz con personajes de escaso nivel cultural que actúan, eso sí, en una escena de máxima inmediatez comunicativa. Como dijimos anteriormente, esas situaciones, caracterizadas por la falta de planificación que tratan de simular, constituyen el entorno "natural" para que afloren, como ejemplos de espontaneidad, rasgos marcados diatópicamente y considerados de poco prestigio diastráticamente.

(5) Adscribir determinados sectores comerciales. Íntimamente relacionado con lo anterior, nos encontramos con la vinculación que se establece entre modalidad andaluza y sector comercial. Si excluimos los micro-espacios publicitarios "Ser empresarios. Negocios que funcionan", los ejemplos que hemos encontrado pertenecen al sector de la limpieza (quitamanchas "el Milagrito"), de la higiene y cosmética (perfumerias "Ana"), de la reparación (cerrajeria "Macarena"), de la albañilería-construcción y de la alimentación (patatas "Hispalanas").

(6) Lograr un efecto humorístico a partir del empleo de voces fácilmente atribuibles a personajes mediáticos del ámbito local (bien porque lo son realmente,

17 Embutidos Molina: https://www.youtube.com/watch?v=p740GUVtqyc. 18 Fabada Litoral: https://www.youtube.com/watch?v=4WXgsiOxcpw. 
bien por imitación). Es lo que sucede, por ejemplo, con los humoristas "Los Morancos", que dan voz a algunas cuñas radiofónicas o a los imitadores de Lopera, en los anuncios de la estación de servicio "La Catria". En otras ocasiones, el efecto humorístico se logra a partir del empleo de la modalidad andaluza en tipologías discursivas vinculadas a referentes culturales locales, tal y como ocurre en el anuncio de recambios "Castaños" con la llamada del capataz a los costaleros que portan un paso en Semana Santa:

\author{
Hablante 1 (hombre): ¡Castañooo! \\ Hablante 2 (hombre): ¡Dime, miarma! \\ Hablante 1 (hombre): Esta levantá se la vamo ${ }^{\mathrm{h}}$ a dedicar a to $10^{\mathrm{h}}$ que \\ reparan y ahorran como tú, que compran sus pieza ${ }^{\mathrm{h}}$ en recambio ${ }^{\mathrm{h}}$. \\ "Castaño" y por poco dinero tienen sus electrodométicos funcionan- \\ do de nuevo. ¡A estaaa es! \\ Voces costaleros: ¡Reparo y ahorro!, ¡Reparo y ahorro!... \\ Voz en off 1 (hombre): "Recambios Castaño". \\ Voz en off 2 (hombre): Polígono San Jerónimo, 29, junto a Nuevo Torneo. \\ Voz en off 1 (hombre): recambiocastanos.com.
}

En este sentido, también constituye una conversación prototípica una discusión acalorada en torno a un supuesto penalti, contextualizado en un derbi Sevilla- Betis. Es lo que ocurre en la cuña radiofónica de patatas "Hispalana". En este último ejemplo llama la atención cómo el paso gradual y progresivo de una modalidad marcada (reflejada en la pérdida de -d- intervocálica) hacia otra más estándar (con pronunciación plena y marcada de las -s) es simultáneo al paso de un estado emocional de tensión dramática a otro de corte más racional por parte de los interlocutores.

Hablante 1: ¡Penalti! ¡Ha sio Penalti!

Hablante 2: ¡Anda ya! ¡Picinazo! ¡Si no la ha tocao! [ruido de patatas al masticar].

Hablante 1: Estas patatas "Hispalanas" están buenísimas.

Hablante 2: Pues es verdad, ¿eh?

Hablante 1: A lo mejor se tira.

Hablante 2: $\mathrm{mmmm}$..., riquísimas. No, no, que ahora sí veo claro el penalti.

Voz en off (hombre): Seas bético o sevillista, practica el juego limpio con patatas fritas "Hispalana". El próximo partido equipa tu mesa con patatas fritas "Hispalana".

Cien por cien artesanas y cien por cien sevillanas.

\title{
4. Conclusiones
}

La caracterización lingüística andaluza desempeña un papel fundamental como vector de aproximación en la publicidad actual, al establecer un vínculo lingüístico con el potencial consumidor, que se siente identificado con el producto, con los sujetos discursivos del anuncio o con la escena de vida que este representa. Es posible que en este sentido exista una cierta permeabilidad de las campañas electorales (donde siempre ha sido habitual la "oralización" como estrategia de proximidad) hacia la publicidad comercial, en la que la caracterización lingüística de los sujetos discursivos contribuye a acercar el referente publicitado y a lograr el efecto de la identificación.

En la actualidad, la publicidad se erige en un medio de comuni- 
cación muy poderoso, omnipresente, que, lejos de limitarse a ofrecer productos, crea realidades. Este conjunto de contenidos simbólicos se interioriza por parte del imaginario colectivo sin necesidad de razonamiento a través de la asociación simplificada y de la repetición. Tras el análisis del corpus, se observa que en la práctica discursiva publicitaria actual la lengua (y sus modalidades) dejan de tener exclusivamente un valor instrumental para constituirse en verdaderas señas de identidad colectivas a partir de su potencial cohesivo conformador de estereotipos. Dentro del mosaico de variedades internas del español, la modalidad andaluza ha sido una de las más utilizadas a partir de la conformación de un andaluz prototípico que no da cuenta de la heterogeneidad idiomática de la región. Así, por ejemplo, en la mayoría de los anuncios analizados esta conformación de rasgos origina un andaluz alejado de los parámetros de la distancia comunicativa que fomenta la caracterización de personajes con escasa competencia lingüística para el ámbito más formal, adscritos a la esfera doméstica, al sector de la higiene, de la construcción o vinculados a espacios festivos. En estos casos, es habitual encontrar rasgos de pronunciación que no gozan de prestigio: pronunciación fricativa de la ch, pérdida generalizada de la - d- intervocálica (no exclusivamente en participios), pérdida de la $-\mathrm{d}$, ceceo, aspiración de $-\mathrm{s}$ implosiva y final, igualación de $-\mathrm{R}$ y $-\mathrm{L}$ implosivas y apócopes ([5]: pa la chaqueta, pa el pantalón). Frente a esta situación, en el ámbito de los servicios médicos, solo aparecen la pronunciación aspirada de / $\mathrm{x} /$, la distinción $\mathrm{s} / \mathrm{z}$ y el seseo en uno de los casos, rasgos utilizados por hablantes de cualquier condición social y que carecen de juicios sociales negativos. De esta manera, los valores de prestigio, estatus social y poder adquisitivo se extrapolan del sujeto discursivo al producto o servicio que se está publicitando.

De los comportamientos lingüísticos de los personajes que intervienen en los anuncios analizados se extraen algunas conclusiones, a mi entender significativas. Se sigue fomentando el sentimiento que relaciona andaluz e incultura, al tipificar estereotipos sociales asociados a lo vulgar y a las clases más desfavorecidas.

"Es sabido que la postergación y el atraso de la región andaluza han sido
fundamentalmente de carácter económico, social y cultural, al haber esta-
do secularmente inmersa en lo que ha dado en llamarse círculo infernal de
la miseria: la pobreza lleva a la falta de educación, esta a la expresión tosca
y rudimentaria, consecuencia de lo cual es la marginación y, en definitiva,
la permanencia en la pobreza. El sentimiento (más que complejo) de inferio-
ridad de una parte de los andaluces no fue ni es principalmente lingüístico,
aunque, claro es, en los usos lingüísticos se refleja la falta de instrucción y
de educación vinculada a las penurias económicas" (Narbona 2009: 44).

Queda para un análisis futuro contrastar si las modalidades de otras zonas del ámbito hispanohablante se vinculan igualmente a las realidades que hemos constatado en este breve análisis o si, dentro de la fragmentación dialectal del español, este papel se ha fosilizado como intrinsecamente protagonizado en exclusiva por las hablas andaluzas y la carga simbólica que han acarreado secularmente. 


\section{REFERENCIAS}

ADAM, J. M. \& BONHOMME, M. (2000): La argumentación publicitaria. Retórica del elogio y de la persuasión, Madrid: Cátedra. [orig. En fr. (1997): L'argumentation publicitaire. Rhetórique de l'eloge et de la persuasion. Paris: Éditions Natham].

BÜRKI, Y. (2005): La publicidad en escena. Análisis pragmático-textual del discurso publicitario de revistas en español. Zaragoza: Pórtico.

ESCRIBANO HERNÁNDEZ, A. (2018): La redacción publicitaria, Madrid: Sintesis.

FERRAZ MARTÍNEZ, A. (2004): El lenguaje de la publicidad. Madrid: Arco/Libros. GÓMEZTORREGO, L. \& ROBLESÁVILA, S. (2014): Transgresiones idiomáticas en el lenguaje de la Publicidad, Madrid: Cátedra. GUTIÉRREZ ORDÓÑEZ, S. (1997): Comentario pragmático de textos publicitarios, Madrid: Arco/ Libros (Colección Comentario de texto).

HERNANDO CUADRADO, L. A. (1984): El lenguaje de la publicidad, Madrid: Editorial Coloquio.

KOCH, P. \& OESTERREICHER, W. (1990 [2007]): Lengua hablada en la Romania: español, francés, italiano, Madrid: Gredos, 2007 [Traducción de Araceli López Serena del original alemán Gesprochene Sprache in der Romania: Französisch, Italienich, Spanisch. Tubinga: Max Niemeyer].

LASSO DE LA VEGA MENÉNDEZ, C. (2005): La imagen de Andalucía en el discurso publicitario, Sevilla: Centro de Estudios Andaluces.

LÓPEZ SERENA, A. (2013): "Variación y variedades lingüísticas: un modelo teórico dinámico para abordar el estatus de los fenómenos de variación del español hablado en Andalucía", en Narbona Jiménez, pp. 73-127. MÉNDEZ GARCÍA DE PAREDES, E. (1997): "Reivindicación de las hablas andaluzas en la prensa regional durante la transición", en Cano Aguilar, R. (coord.), Las hablas andaluzas. Número monográfico de Demófilo. Revista de Cultura Tradicional de Andalucía (Sevilla: Fundación Machado), 22, pp. 155-181. MÉNDEZ GARCÍA DE PAREDES, E. (2003): "El andaluz en la prensa (actitudes lingüísticas: 1980-1981)", en Narbona, A. (coord.), Actas de las II Jornadas sobre el Habla Andaluza, 2, Estepa (Sevilla): Ayuntamiento de Estepa, pp. 139-173.

MÉNDEZ GARCÍA DE PAREDES, E. (2009): "La proyección social de la identidad lingüística de Andalucía. Medios de comunicación, enseñanza y política lingüística", en Narbona Jiménez, A. (coord.), pp. 213-319.

MÉNDEZ GARCÍA DE PAREDES, E. (2019): "Posiciones enunciativas e ideología en los discursos metalingüísticos sobre la variedad andaluza en la prensa española. De 1977 a la actualidad", en Marimón Llorca, C. y Santamaría Pérez, I. (eds.), Ideologias sobre la lengua $y$ medios de comunicación escritos. El caso del español. Berlin: Peter Lang, pp. 193-215. MORILLO-VELARDE PÉREZ, R. (2003): "Imagen estereotípica, imagen geográfica e imagen estadística del andaluz", en Carmen Lucía Reina Reina y Antonio Narbona Jiménez 
(coords.), Actas de las II Jornadas sobre el habla andaluza. El español hablado en Andalucía. Ayuntamiento de Estepa, pp. 107-137.

MORILLO-VELARDE PÉREZ, R. (2011): "La pronunciación", en Rafael Cano Aguilar, Antonio Narbona y Ramón Mori1lo-Velarde Pérez (coords.): El español hablado en Andalucía, Sevilla: Editorial Universidad de Sevilla, pp. 165-220.

NARBONA JIMÉNEZ, A. (coord.) (2009): La identidad lingüistica de Andalucía, Sevilla: Centro de Estudios Andaluces. NARBONA JIMÉNEZ, A. (2013): Conciencia y valoración de las hablas andaluzas, Sevilla: Universidad Internacional de Andalucía.
REY, J. (1999): Palabras para vender, palabras para soñar. Introducción a la redacción pu blicitaria. Barcelona: Paidós.

ROBLES ÁVILA, S. (2004a): Realce y apelación en el lenguaje de la publicidad. Madrid: Arco Libros.

ROBLES ÁVILA, S. (2004b): "La recreación de lo coloquial en el español de la publicidad", Analecta Malacitana: Revista de la Sección de Filología de la Facultad de Filosofia y Letras, vol. 27(2), pp. 541-586.

ROBLES ÁVILA, S. \& ROMERO, M. ${ }^{a}$ V. (coords.) (2010): Publicidad y lengua española: un estudio por sectores, Sevilla: Comunicación Social. 